\title{
Systematic Approach to Training for Design of Nuclear Power Plant Decommissioning Training in South Korea
}

\author{
Jeong Keun Kwak \\ Korea Hydro \& Nuclear Power Co. (KHNP), Global Technical Education Team, 658-91 Haemaji-ro, Seosaeng-myeon, Ulju-gun, \\ 45014, Ulsan, South Korea
}

\begin{abstract}
In 1979, unavailability of MFWS (Main Feedwater System) in TMI (Three Mile Island) Unit-2 happened in the United States. To make it worse, due to malfunction of Isolation Control Valves in AFWS (Auxiliary Feedwater System), the supply of cooling water to SGs (Steam Generators) was delayed approximately 8 minutes compared to AOP (Abnormal Operating Procedure). In the long run, on account of deferred heat sink provision to SGs, the reactor core was melted partially. It was the first critical accident in the US commercial NPP (Nuclear Power Plant) history. Hence, after TMI Accident, US NRC (Nuclear Regulatory Committee) suggested more than one hundred alternatives to improve safety and reliability of NPP. Among these countermeasures, one proposal was related to training area. It was SAT (Systematic Approach to Training) methodology. Therefore, the goal of SAT is the enhancement of NPP stability through training point of view. Since the appearance of SAT in the nuclear industry, it has acquired the unwavering position in the US NPP training field. Meanwhile, significance of NPP decommissioning has been soared up in South Korea since the announcement of Kori Unit-1 decommissioning decision. According to the proclaimed plan from Korean government, Kori Unit-1 is scheduled to be decommissioned from June, 2017. Under this circumstance, nurturing sufficient number of NPP decommissioning engineers is one of the most urgent issues in South Korean nuclear industry. Hence, to elevate efficiency and consistency of training quality, SAT methodology can be a reliable solution for the training of decommissioning engineers. For this reason, the present study aims to design SAT based NPP decommissioning engineer training in South Korea.
\end{abstract}

Key words: Systematic Approach to Training, nuclear power plant, decommissioning, US nuclear regulatory committee, Three Mile Island Unit-2.

\section{Introduction}

Generally speaking, operation, maintenance and oversight of NPPs (Nuclear Power Plants) which are equipped with a great number of mechanical equipment, electrical devices and gauging instruments require sophisticated and sensitive approaches, intrinsically. Hence, to prevent unexpected events or accidents in NPP which are originated from complexity, a variety of proactive methods have been taken into consideration since the first commercial NPP located in Calder Hall, the United Kingdom. Among diverse trouble preventative ways, training has played one of the most significant roles to reinforce safety and reliability of NPP. This is the reason why

Corresponding author: Jeong Keun Kwak, M.S., senior manager \& instructor, research field: decommissioning of nuclear power plant. nuclear industry in every country has established and maintained its own training methodologies and institutes.

After TMI Accident, which was the first severe accident in the world commercial NPPs before the Chernobyl case, there were more than one hundred proposals to enhance durability and stability of NPP by the USNRC (United States Nuclear Regulatory Commission). In submitted suggestions, one proposal was related to personnel training in NPP which was SAT (Systematic Approach to Training). And this methodology was adopted in the US NPP industry, immediately. Since then, SAT has been the unwavering fundamental guideline in the field of NPP employee training in the US.

In South Korea, since the announcement of Kori Unit-1 shutdown in June 2015, NPP decommissioning 
has been a highlighted sector in Korean nuclear industry. After the proclamation of Kori Unit-1 permanent shutdown, diverse technological and regulatory preparations have been sped up. Thus, to keep abreast of current environment in NPP field, training for NPP decommissioning engineers should be designed and implemented as well. However, concrete and indispensable training standard and criteria for NPP decommissioning have not been settled down in South Korea, yet. Therefore, on the basis of current surroundings of Korean nuclear industry, the present study has been performed to develop SAT grounded training for NPP decommissioning engineers in South Korea, especially, employees in KHNP (Korea Hydro \& Nuclear Power Co.).

\section{Systematic Approach to Training}

In this section, rudimentary knowledge is used for the description of SAT background. In particular, the fundamental structure of SAT is what is called ADDIE. ADDIE stands for Analysis, Design, Development, Implementation and Evaluation. Therefore, through the sequence of ADDIE, basic process for SAT can be expounded.

\subsection{Origin and Appearance of SAT}

The year 1979, TMI Accident, the worst accident in commercial NPPs history occurred in the US. First, on account of main feedwater pumps shutdown, SGs (Steam Generators) lost basic function for heat sink. Second, unlike with NPP safety system design, AFWS was not actuated automatically due to fixation of Isolation Control Valves. For this reason, cooling water was supplied to Steam Generators 8 minutes later since the beginning of an event. Consequently, NPP reactor core was damaged partially and a great amount of radioactive materials was emitted to the environment. As a matter of fact, the result of TMI Accident was different with most of nuclear experts' prediction for LOFW (Loss of Feedwater) event.
Therefore, it was proven that NPP was not safe enough and there was always a possibility of huge catastrophe. Actually, after 7 years since TMI Accident, the most severe accident occurred in Chernobyl NPP located in USSR (Union of Soviet Socialist Republics). Hence, TMI Accident served as a momentum to raise public awareness and industrial safety in NPP. As a result, through investigations of this disaster, more than one hundred alternatives were proposed by the USNRC. Among diverse measures, SAT applied training was one solution to elevate safety and reliability of NPP. This was the origin of SAT in the world [1].

On the other hand, before NPPs export to UAE (United Arab Emirates) in 2009, NPP employee training in South Korea, specifically, KHNP was far from SAT methodology. However, in the contract document for NPPs export to UAE, there was one sentence related to SAT grounded training. “Operating services contractor shall ensure that approved (accredited) training programs are developed, established, implemented and maintained using a Systematic Approach to Training (SAT)." This sentence was an initiation of SAT methodology application in the field of NPP employee training in South Korea.

\subsection{Indispensability of SAT}

The operation and maintenance of NPP request the highest level of employee performance. Demanded levels for employee competence could be acquired when training improves personal knowledge and skills which are compulsory for safe and effective job performance. Hence, for the purpose of employee cultivation in NPPs, structured training methods are necessary. In this viewpoint, SAT methodology can be a clear and definite solution. Because, the use of SAT offers significant advantages over conventional, curricula-driven training in terms of training efficiency and management control [2].

Additionally, performance-based SAT methodology 
secures consistency of training quality. In other words, regardless of instructor's ability and change of training surroundings, training expectations for trainees' achievements can be maintained in equal condition. Because, SAT based training is only dependent on holistically analyzed training materials instead of instructors' individual skills, knowledge and experiences.

\subsection{Fundamental Synopsis of SAT}

SAT is a systematic access that supplies a logical process from the analysis of competencies required to perform jobs for analysis, design, development and implementation to accomplish performance and subsequent evaluation of trainings [3]. Basically, SAT is composed of five stages: Analysis, Design, Development, Implementation and Evaluation, what is so-called ADDIE. Next Fig. 1 exhibits a schematic diagram of SAT process in NPP [4].

\subsubsection{Analysis}

Analysis stage defines occurred troubles or necessary requirements to verify possible causes and appropriate solutions which best fit needs of an organization. When training is selected as one part of an alternative, the analyst gathered data which play a significant role as the foundation for structured development of performance-based training program. There are three major activities in Analysis level.

- Need Analysis;

- Job Analysis;

- Task Analysis.

First, Need Analysis is a concrete clarification of resource requirements, performance effectiveness and identifying solutions which satisfy requirements or get rid of insufficiency. Second, based on Need Analysis outcome, Job Analysis creates a list of valid tasks and performance indicators such as DIF (Difficulty, Importance and Frequency) rating for IT (Initial Training) or CT (Continuing Training). Third, Task Analysis is division of a work into manageable level, which is called element. Also, Task Analysis regulates skills and knowledge which are required by trainees to carry out practical implementation of tasks [5].

\subsubsection{Design}

In the previous Analysis stage, performance-based training is constructed through an analysis of need, job

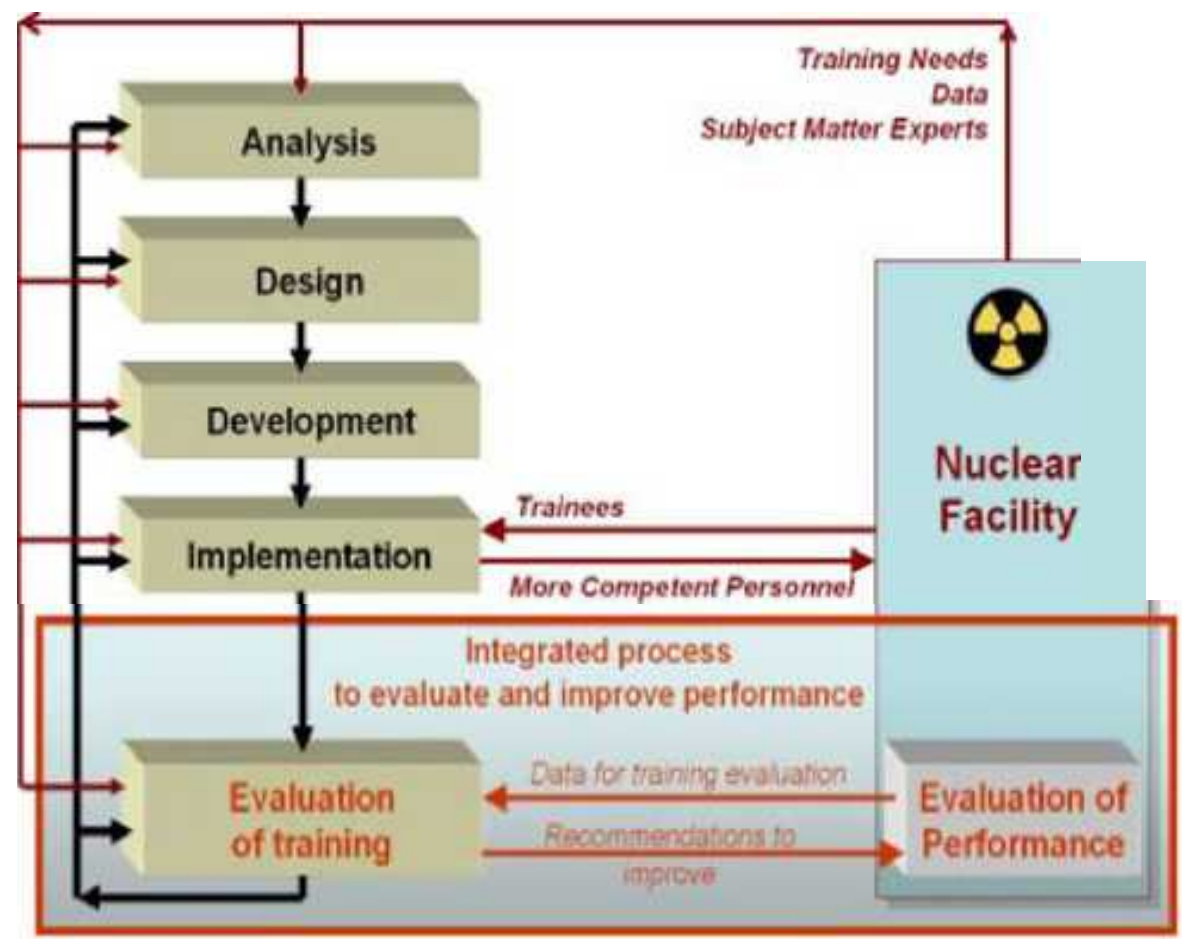

Fig. 1 Diagram of SAT process in NPP employee training. 
and task to determine appropriate knowledge and skills, which are essential for SAT. During Design phase, chosen knowledge and skills are used to generate specific outcomes for next Development, Implementation and Evaluation stages in the process of training. In particular, to supply effective training materials such as learning objectives, training setting and test items, systematic design specification or document so-called JTA (Job and Task Analysis) form should be developed. In this point, created results must be traceable to practical task performance demands. There are six main considerations in Design step.

- Learning objectives;

- Training setting;

- Test items;

- Training plan;

- Expected trainee entry level skills and knowledge;

- JPM (Job Performance Measure).

\subsubsection{Development}

Development stage is established to accomplish training effectiveness and efficiency in the field. In the Development stage, training materials are arranged to guide instructors and trainees. There are three major points in Development level.

- Specification of learning activities;

- Development of training materials;

- Selection of training methods.

\subsubsection{Implementation}

In Implementation stage, training programs are applied into actual training venue. Namely, previously finished Analysis, Design and Development outcomes are carried out practically in Implementation step. There are three main aspects in Implementation level as below.

- Conduct of training;

- Conduct of in-training evaluation;

- Documentation of training.

2.3.5 Evaluation

From the beginning of Analysis stage to the realization of Implementation step, trainees' and instructors' accomplishments should be assessed at the same time. Therefore, in each step, obtained evaluation results are applied to improve quality of training materials and concerning activities. In Evaluation stage, there are three significant factors to be deliberated [3].

- Indicator monitoring;

- Information analysis;

- Corrective actions.

Next Fig. 2 describes mutual feedback to each stage through Evaluation stage [6].

\section{Analysis for Nuclear Power Plant Decommissioning Training}

In this chapter, application of SAT for the design of NPP decommissioning engineers training in South Korea is elucidated. Decommissioning engineers are

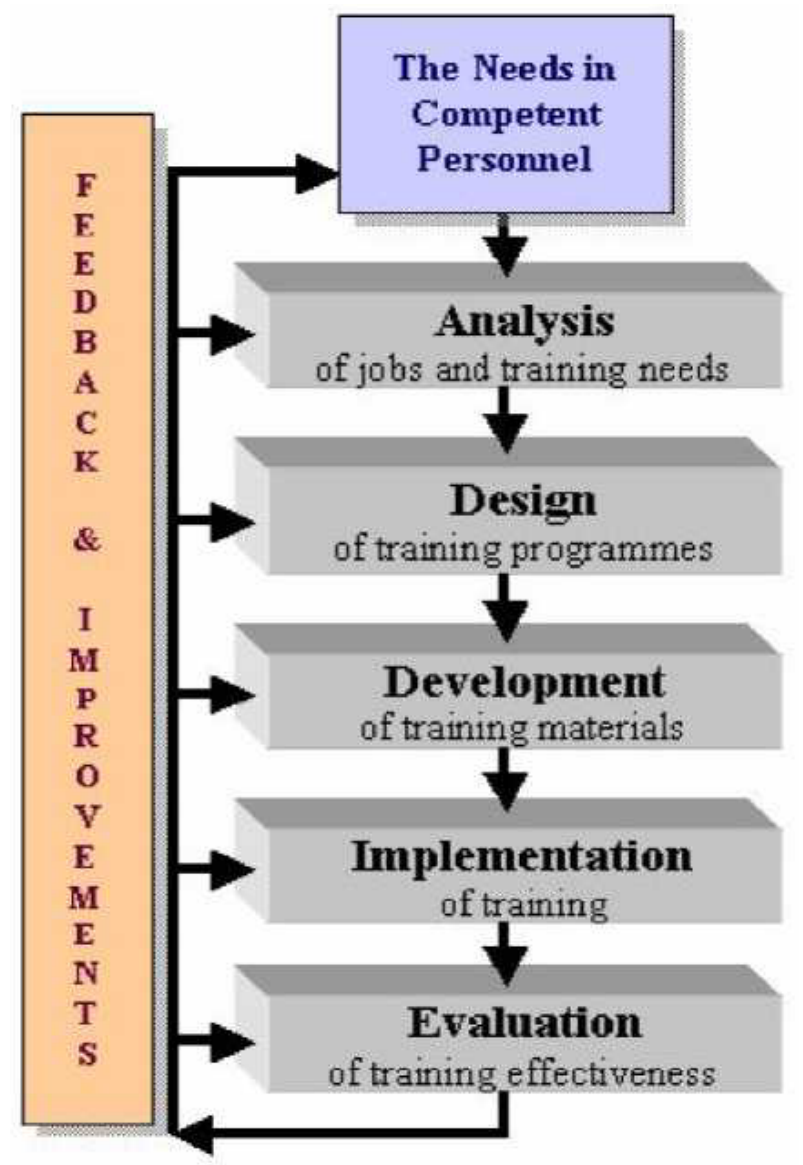

Fig. 2 Evaluation feedback to each stage. 
responsible for preparations of initial NPP decommissioning to the recovery of NPP site to the nature or industrial complex, so-called site remediation. And this is achieved in consideration of domestic regulations, preliminary and post-shutdown decommissioning reports, physical dismantling activities, chemical or radiological decontamination and final site remediation through FSS (Final Site Survey) [7]. Hence, to arrive at the final destination of NPP decommissioning project in South Korea, training design for NPP decommissioning engineers should be not only holistically structured but also developed in detail.

\subsection{Analysis_-Job and Task Analysis}

In chapter 2.3.1, Job Analysis is defined to a production of a list of valid tasks and performance indicators for IC and CT. And Task Analysis is division of a unit work into manageable level. Hence, on the basis of JTA definitions, yielded actual tasks for NPP decommissioning engineers are exhibited in Table 1.

In consideration of practical JTA for NPP decommissioning engineer, concrete eighteen tasks are selected. For the determination of eighteen tasks, domestic and overseas documents for NPP decommissioning from IAEA (International Atomic Energy Agency), DOE (Department of Energy) in the US, USNRC, Korean Atomic laws and other major materials were referred. In addition, decided tasks are deepened down to the differentiated elements. Here, element means subdivided activities from each task.

Therefore, one task can be divided into two or more elements. In conclusion, through the finalization of eighteen tasks and related elements determination for South Korean NPP decommissioning engineers, Analysis stage is completed.

\subsection{Design-Consideration Factors}

In Design phase, several aspects shall be deliberated such as learning objectives, training setting, test items, training plan, expected entry level knowledge and skills and JPM (Job Performance Measure) which could be compulsory. Among these consideration factors, for the application to newly developed document called JTA form, a few constituents are deliberated and displayed in Table 2.

Table 1 Determined task for the training of NPP decommissioning engineers.

\begin{tabular}{ll}
\hline Task code & Task name \\
\hline DE-T001 & Consider fundamental knowledge for NPP decommissioning. \\
DE-T002 & Review foreign experiences for NPP decommissioning. \\
DE-T003 & Examine domestic experiences for nuclear facilities decommissioning. \\
DE-T004 & Organize human resources, training and document structure for NPP decommissioning. \\
DE-T005 & Describe fundamental policy of domestic NPP decommissioning. \\
DE-T006 & Explain project management for NPP decommissioning. \\
DE-T007 & Review necessary regulations for foreign NPP decommissioning. \\
DE-T008 & Review compulsory regulations for domestic NPP decommissioning. \\
DE-T009 & Establish DP (Decommissioning Planning) for domestic NPP decommissioning. \\
DE-T010 & Review spent fuels management of foreign NPP decommissioning. \\
DE-T011 & Look into spent fuels management of domestic NPP decommissioning. \\
DE-T012 & Suggest technology development roadmap for domestic NPP decommissioning. \\
DE-T013 & Describe dismantling technology for structures and components. \\
DE-T014 & Explain decontamination technology for structures and components. \\
DE-T015 & Consider site remediation at the final stage of NPP decommissioning. \\
DE-T016 & Elucidate radiological characterization through decommissioning activities. \\
DE-T017 & Account for NPP decommissioning wastes management. \\
DE-T018 & Evaluate the cost for NPP decommissioning. \\
\hline DE: & Decommissioning Engineer \\
\hline
\end{tabular}


In Table 2, condition is working environments for task performing using documents, books and computerized devices. Standard is specific reference materials. Knowledge and skills are imperative information or experiences for training. However, in Analysis stage, knowledge and skills were already determined. Hence, obtained knowledge and skills are incorporated to JTA form in the stage of Design. Learning objectives are purposes of training and required final achievements at the end of training activities. Training setting means types of training, for example classroom, simulator, laboratory and OJT (On-the-Job Training). Finally, the establishment of JTA form means the completion of Design stage.

\subsection{Development-Preparations Based on JTA Form}

After the completion of JTA form, next step is to guarantee effectiveness of designed training. Specified ways for learning activities, application of audiovisual media, useful methods for training progression are set up in the step of Development. Therefore, Table 3 displays a variety of preparations for an accomplishment of efficient decommissioning engineers training.

\subsection{Implementation and Evaluation-Training} Fulfillment and Feedback

From Analysis stage to Development step, all preparations for NPP decommissioning engineers training are finalized. Hence, the left levels in SAT process are Implementation and Evaluation. Implementation means a process of putting training programs into an actual training field for example, classroom, laboratory, OJT even CBT (Computer Based Training). In practical, through Design stage, training types for NPP decommissioning engineers are already determined. Therefore, previously settled training type for South Korean decommissioning engineers will be just performed in the classroom and OJT.
On the other hand, when it comes to overall SAT sequence, Evaluation is the next stage of Implementation and it is a final step in SAT. However, Evaluation step is interactive with four previous stages to secure training effectiveness for competent employees training at the same time. Therefore, Table 4 materializes acquired evaluation feedbacks from each stage design for the training of decommissioning engineers in South Korea. Also obtained outcomes are already reflected and applied the actual decommissioning engineer training design process.

Table 2 JTA form for NPP decommissioning engineers.

\begin{tabular}{|l|l|}
\hline Item & Description \\
\hline Task code & Task number \\
\hline Task name & Clarification of task \\
\hline Element & Departmentalization of a task \\
\hline Condition & Training circumstance \\
\hline Standard & Reference procedures and documents \\
\hline Knowledge/skills & Plant information and work experiences \\
\hline Learning objective & Final goal of training \\
\hline Training setting & Type/location for training \\
\hline
\end{tabular}

Table 3 Preparations to improve training efficiency.

\begin{tabular}{|l|l|}
\hline Item & Description \\
\hline $\begin{array}{l}\text { Specification of } \\
\text { learning activity }\end{array}$ & $\begin{array}{l}\text { Classroom expectations } \\
\text { Evaluation methods } \\
\text { Safety moment }\end{array}$ \\
\hline $\begin{array}{l}\text { Development of } \\
\text { training material }\end{array}$ & $\begin{array}{l}\text { Big picture for overall topic } \\
\text { Introductory video clip } \\
\text { Summarization of learning objectives }\end{array}$ \\
\hline $\begin{array}{l}\text { Selection of } \\
\text { training method }\end{array}$ & $\begin{array}{l}\text { Classroom lecture } \\
\text { Case study and discussions } \\
\text { OJT }\end{array}$ \\
\hline
\end{tabular}

Table 4 Feedbacks through Evaluation stage.

\begin{tabular}{|l|l|}
\hline Stage & Feedback \\
\hline Analysis & $\begin{array}{l}\text { Deeper fractionation of each task } \\
\text { Perspicuity of quantitative elements } \\
\text { Resetting of IT and CT based on DIF rating }\end{array}$ \\
\hline Design & $\begin{array}{l}\text { Transition of training setting from classroom } \\
\text { to OJT Consistency between learning } \\
\text { objectives and referred training document } \\
\text { Establishment of reasonable test items } \\
\text { Efficient safety moment application }\end{array}$ \\
\hline Development & $\begin{array}{l}\text { Change of training methods Additional } \\
\text { review for conduct of training }\end{array}$ \\
\hline Implementation & Structured documents storage \\
\hline
\end{tabular}




\section{Conclusion}

The purpose of current study is to design SAT based training for NPP decommissioning engineers in South Korea, in particular, KHNP. Since NPPs export to UAE in 2009, SAT methodology has been adamant trend in the training of South Korean nuclear industry. For this reason, to develop training for NPP decommissioning engineers based on SAT, most of all, SAT structure so-called ADDIE, is examined. That is to say, origin, appearance, meaning and five stages of SAT are elucidated in gradual. On the basis of these theoretical background deliberations, practical and applicable results have been generated for the design of NPP decommissioning engineers, including JTA (Job and Task Analysis), consideration factors for JTA form, preparations based on JTA outcomes and training fulfillment and feedback in sequence. Taken together, SAT grounded training for NPP decommissioning engineers in South Korea is materialized systematically.

\section{Acknowledgments}

The author would like to express the deepest gratitude to Bae Joo Kim who is a general manager in
Kori Nuclear Site-1, KHNP, South Korea. Without his knowledgeable instructions and thoughtful insight to SAT concept, it could not be possible to accomplish present study outcome.

\section{References}

[1] United States Nuclear Regulatory Committee (USNRC). 1980. NUREG-0737, Clarification of TMI Accident Plan Requirements. Washington DC.

[2] International Nuclear Power Operator (INPO). 1998. ACAD 85-006, Principles of Training System Development. Atlanta.

[3] International Atomic Energy Agency (IAEA). 1998. IAEA-TECDOC-1057, Experience in the Use of Systematic Approach to Training (SAT) for Nuclear Power Plant Personnel. Vienna.

[4] International Atomic Energy Agency (IAEA). 2009. Overview of IAEA Guidance the Systematic Approach to Training (SAT). Tom Mazour.

[5] International Atomic Energy Agency (IAEA). 1994. Guidebook on Training to Establish and Maintain the Qualification and Competence of Nuclear Power Plant Operations Personnel. Vienna.

[6] International Atomic Energy Agency (IAEA). 2008. No. NG-T-2.3, Decommissioning of Nuclear Facilities Training and Human Resource Considerations. Vienna.

[7] International Atomic Energy Agency (IAEA). 2000. TRS No. 399, Organization and Management for Decommissioning of Large Nuclear Facilities. Vienna. 